\title{
Chinese terms and pronunciations
}

(in Pinyin order)

\section{Terms}

安徽

澳门

八国联军

八议

百花齐放

百日维新

拜上帝会

北伐

北京

被派遣劳动者

北洋

比

部门规章

裁定

裁决

长安

长征

朝廷

承包

成吉思汗

程䝠

敕

重庆

楚汉相争

初级人民法院

初级审判厅

垂帘听政

《春秋》

\section{Pinyin}

ān hū

ào mén

bā guó lián jūn

bā yì

băi huā qí fàng

băi rì wéi xīn

bài shàng dì huì

běi fá

běi jīng

bèi pài qiăn láo dòng zhě

běi yang

bì

bù mén guī zhāng

cái dìng

cái jué

cháng ān

cháng zhēng

cháo tíng

chéng bāo

chéng jí sī hán

chéng yí

chì

chóng qìng

chǔ hàn xiàng zhēng

chū jí rén mín fă yuàn

chū jí shěn pàn tīng

chuí lián tīng zhèng

chūn qiū 


\begin{tabular}{|c|c|}
\hline 慈禧太后 & cí xǐ tài hòu \\
\hline 村民委员会 & cūn mín wěi yuán huì \\
\hline 大理院 & dà lǐ yuàn \\
\hline 大连 & dà lián \\
\hline 《大清新刑律》 & dà qīng xīn xíng lǜ \\
\hline 大调解 ～～～～～～～～～～ & dà tiáo jiě \\
\hline 《大学》 & dà xué \\
\hline 大禹 & dà yǔ \\
\hline 大跃进 & dà yuè jìn \\
\hline 大运河 & dà yùn hé \\
\hline 单行条例 & dān xíng tiáo lì \\
\hline 道 & dào \\
\hline 倒查问责制 & dào chá wèn zé zhì \\
\hline 《道德经》 & dào dé jīng \\
\hline 道家 & dào jiā \\
\hline 道教 & dào jiào \\
\hline 德 & dé \\
\hline 德治 & dé zhì \\
\hline 邓小平 & dèng xiăo píng \\
\hline 邓小平理论 & dèng xiăo píng lǐ lùn \\
\hline 地方审判厅 & dì fāng shěn pàn tīng \\
\hline 地方性法规 & dì fāng xìng fă guī \\
\hline 地方政府规章 & dì fāng zhèng fǔ gūi zhāng \\
\hline 敌我之间的矛盾 & dí wǒ zhī jiān de máo dùn \\
\hline 顶替 & dǐng tì \\
\hline 董仲舒 & dǒng zhòng shū \\
\hline 对内改革 对外开放 & duì nèi găi gé duì wài kāi fàng \\
\hline 法 & fă \\
\hline 法家 & fă jiā \\
\hline 《法经》 & fă jīng \\
\hline 《法律答问》 & fă lǜ dá wèn \\
\hline 法院调解 & fă yuàn tiáo jiě \\
\hline 法治 & fă zhì \\
\hline 法治中国 & fă zhì zhōng guó \\
\hline 反右运动 & făn yòu yùn dòng \\
\hline 非攻 & fēi gōng \\
\hline 分流 + 调解 + 速裁 + 快审 & fēn liú tiáo jiě sù cái kuài shěn \\
\hline
\end{tabular}




\begin{tabular}{|c|c|}
\hline 焚书坑儒 & fén shū kēng rú \\
\hline 封建 & fēng jiàn \\
\hline 风水 & fēng shuǐ \\
\hline 夫妇 & fū fù \\
\hline 父子 & fù zǐ \\
\hline 甘肃 & gān sù \\
\hline 高等审判厅 & gāo děng shěn pàn tīng \\
\hline 高级人民法院 & gāo jí rén mín fă yuàn \\
\hline 格 & gé \\
\hline 个体经济 & gè tǐ jīng jì \\
\hline 个体户 & gè tǐ hù \\
\hline 工 & gōng \\
\hline 公安机关 & gōng ān jī guān \\
\hline 共产党 & gòng chăn dăng \\
\hline 公益诉讼 & gōng yì sù sòng \\
\hline 广东 & guăng dōng \\
\hline 广西 & guăng x̄̄ \\
\hline 广州 & guăng zhōu \\
\hline 光绪 & guāng xù \\
\hline 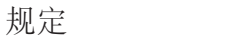 & guī dìng \\
\hline 国家监察委员会 & guó jiā jiān chá wěi yuán huì \\
\hline 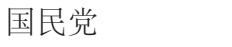 & guó mín dăng \\
\hline 国务院 & guó wù yuàn \\
\hline 海南 & hăi nán \\
\hline 汉 & hàn \\
\hline 韩非 & hán fēi \\
\hline 汉人 & hàn rén \\
\hline 汉武帝 & hàn wǔ dì \\
\hline 汉语 & hàn yǔ \\
\hline 汉字 & hàn zì \\
\hline 杭州 & háng zhōu \\
\hline 红卫兵 & hóng wèi bīng \\
\hline 洪秀全 & hóng xiù quán \\
\hline 忽必烈 & hū bì liè \\
\hline 护法运动 & hù fă yùn dòng \\
\hline 户籍 & hù jí \\
\hline 湖南 & hú nán \\
\hline
\end{tabular}




\begin{tabular}{|c|c|}
\hline 《会典》 & huì diăn \\
\hline 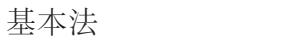 & jī běn fă \\
\hline 家庭联产承包责任制 & jiā tíng lián chăn chéng bāo zé rèn zhì \\
\hline 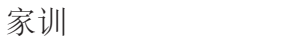 & jiā xùn \\
\hline 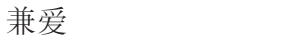 & jiān ài \\
\hline 贱民/贱人 & jiàn mín / jiàn rén \\
\hline 蒋介石 & jiăng jiè shí \\
\hline 江西 & jiāng xī \\
\hline 江泽民 & jiāng zé mín \\
\hline 解释 & jiě shì \\
\hline 金 & jīn \\
\hline 晋 & jìn \\
\hline 晋律 & jìn lǜ \\
\hline 九江 & jiǔ jiāng \\
\hline 居民委员会 & jū mín wěi yuán huì \\
\hline 具体行政行为 & jù tǐ xíng zhèng xíng wéi \\
\hline 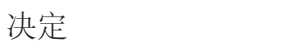 & jué dìng \\
\hline 君臣 & jūn chén \\
\hline 军阀 & jūn fá \\
\hline 君主立宪 & jūn zhǔ lì xiàn \\
\hline 君子 & jūn zì \\
\hline 康熙 & kāng xī \\
\hline 康有为 & kāng yǒu wéi \\
\hline 科 & $\mathrm{ke}$ \\
\hline 克已复礼 & kè jǐ fù lǐ \\
\hline 孔子 & kǒng zǐ \\
\hline 跨行政区划的 & kuà xíng zhèng qū huà de \\
\hline 劳动教养 & láo dòng jiào yăng \\
\hline 劳动争议调解委员会 & láo dòng zhēng yì tiáo jiě wěi yuán huì \\
\hline 劳动争议仲裁委员会 & láo dòng zhēng yì zhòng cái wěi yuán huì \\
\hline 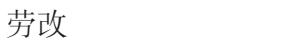 & láo găi \\
\hline 老子 & lăo zǐ \\
\hline 类推 & lèi tū \\
\hline 理 & lǐ \\
\hline 礼 & lǐ \\
\hline 例 & lì \\
\hline 礼法结合 & lǐ fă jié hé \\
\hline
\end{tabular}




\begin{tabular}{|c|c|}
\hline 立法为民 & lì fă wèi mín \\
\hline 立法院 ～～～～～～～～～ & lì fă yuàn \\
\hline 立改废释并举 & lì găi fèi shì bìng jǔ \\
\hline 礼内法外 & lǐ nèi fă wài \\
\hline 李斯 & lǐ sī \\
\hline 理学 & lǐ xué \\
\hline 礼治 & lǐ zhì \\
\hline 梁启超 & liáng qǐ chāo \\
\hline 辽 & liáo \\
\hline 林则徐 & lín zé xú \\
\hline 令 & lìng \\
\hline 刘 邦 & liú bāng \\
\hline 《六典》 & liù diăn \\
\hline 流动人口 & liú dòng rén kǒu \\
\hline 《六法全书》 & liù fă quán shū \\
\hline 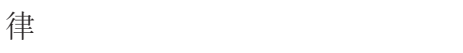 & lǜ \\
\hline 律疏 & lǜ shū \\
\hline 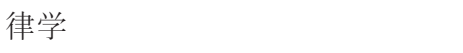 & lǜ xué \\
\hline 马锡五审判方式 & mǎ xī wǔ shěn pàn fāng shì \\
\hline 毛泽东 ～～～～～～～～～ & máo zé dōng \\
\hline 毛泽东思想 & máo zé dōng sī xiăng \\
\hline 《毛主席语录》 & máo zhǔ xí yǔ lù \\
\hline 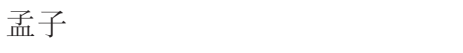 & mèng zǐ \\
\hline 民心 & mín xīn \\
\hline 民主共和 & mín zhǔ gòng hé \\
\hline 民主集中 & mín zhǔ jí zhōng \\
\hline 民主派 & mín zhǔ pài \\
\hline 明 & míng \\
\hline 名不正则言不顺 言不顺则事不成 & $\begin{array}{l}\text { míng bú zhèng zé yán bú shùn yán bú } \\
\text { shùn zé shì bú chéng }\end{array}$ \\
\hline 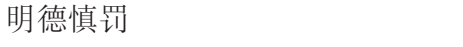 & míng dé shèn fá \\
\hline 墨家 & mò jiā \\
\hline 墨子 & mò zǐ \\
\hline 摸著石头过河 & mō zhe shí tóu guò hé \\
\hline 南北朝 & nán běi cháo \\
\hline 男耕女织 & nán gēng nü zhī \\
\hline 南京 & nán jīng \\
\hline
\end{tabular}




\begin{tabular}{|c|c|}
\hline 能动司法 & néng dòng sī fă \\
\hline 宁波 & níng bō \\
\hline 宁夏 & níng xià \\
\hline 农 & nóng \\
\hline 赔偿委员会 & péi cháng wěi yuán huì \\
\hline 配套规章 & pèi tào guī zhāng \\
\hline 朋友 & péng yǒu \\
\hline 彭真 & péng zhēn \\
\hline 批复 & pī fù \\
\hline 批孔 & pī kǒng \\
\hline 破四旧 & pò sì jiù \\
\hline 溥仪 & pǔ yí \\
\hline 气 & qì \\
\hline 气功 & qì gōng \\
\hline 乾隆 & qián lóng \\
\hline 秦 & qín \\
\hline 《钦定宪法大纲》 & qīn dìng xiàn fă dà gāng \\
\hline 清 & qīng \\
\hline 青岛 & qīng dăo \\
\hline 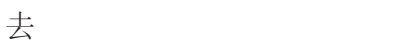 & qù \\
\hline 全国人民代表大会 & quán guó rén mín dài biăo dà huì \\
\hline 全国人民代表大会常务委员会 & $\begin{array}{l}\text { quán guó rén mín dài biǎo dà huì cháng } \\
\text { wù wěi yuán huì }\end{array}$ \\
\hline 全面深化改革 & quán miàn shēn huà găi gé \\
\hline 群众路线 & qún zhòng lù xiàn \\
\hline 仁 & rén \\
\hline 人类命运共同体 & rén lèi mìng yùn gòng tóng tǐ \\
\hline 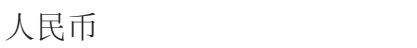 & rén mín bì \\
\hline 人民法院 & rén mín fă yuàn \\
\hline 人民检察院 & rén mín jiăn chá yuàn \\
\hline 人民警察 & rén mín jǐng chá \\
\hline 人民民主专政 & rén mín mín zhǔ zhuān zhèng \\
\hline 人民内部的矛盾 & rén mín nèi bù de máo dùn \\
\hline 人民陪审员 & rén mín péi shěn yuán \\
\hline 人民调解 & rén mín tiáo jiě \\
\hline 人民调解委员会 & rén mín tiáo jiě wěi yuán huì \\
\hline 人情 & rén qíng \\
\hline
\end{tabular}




\begin{tabular}{|c|c|}
\hline 仁学 & rén xué \\
\hline 仁政 & rén zhèng \\
\hline 人治 & rén zhì \\
\hline 儒家 & rú jiā \\
\hline 瑞金 & ruì jīn \\
\hline 三宝 & sān băo \\
\hline 三表法 & sān biăo fă \\
\hline 三反 & sān făn \\
\hline 三纲 & sān gāng \\
\hline 三个代表 & sān gè dài biăo \\
\hline 三国 & sān guó \\
\hline 三民主义 & sān mín zhǔ yì \\
\hline 山东 & shān dōng \\
\hline 陕甘宁边区政府 & shăn gān níng biān qū zhèng fǔ \\
\hline 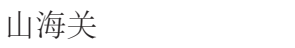 & shān hăi guān \\
\hline 汕头 & shàn tóu \\
\hline 陕西 & shăn xī \\
\hline 商 & shāng \\
\hline 上海 & shàng hăi \\
\hline 上计 & shàng jì \\
\hline 尚同 & shàng tóng \\
\hline 商鞅 & shāng yāng \\
\hline 社会主义法治国家 & shè huì zhǔ yì fă zhì guó jiā \\
\hline 社会主义民主 & shè huì zhǔ yì mín zhǔ \\
\hline 社会主义市场经济 & shè huì zhǔ yì shì chăng jīng jì \\
\hline 社会主义现代化建设 & shè huì zhǔ yì xiàn dài huà jiàn shè \\
\hline 沈家本 ～～～～～～～～～～～～ & shěn jiā běn \\
\hline 审判委员会 & shěn pàn wěi yuán huì \\
\hline 慎刑 & shèn xíng \\
\hline 沈阳 & shěn yáng \\
\hline 深圳 & shēn zhèn \\
\hline 势 & shì \\
\hline 式 & shì \\
\hline 士 & shì \\
\hline 十国 & shí guó \\
\hline 实施细则 & shí shī xì zé \\
\hline 师夷之长技以制夷 & shī yí zhī cháng jì yǐ zhì yí \\
\hline
\end{tabular}




\begin{tabular}{|c|c|}
\hline 世祖 & shì zǔ \\
\hline 术 & shù \\
\hline 恕 & shù \\
\hline 蜀 & shǔ \\
\hline 疏议 & shū yì \\
\hline 水 & shuǐ \\
\hline 舜 & shùn \\
\hline 说法 & shuō fă \\
\hline 丝绸之路 & sī chóu zhī lù \\
\hline 四端 & sì duān \\
\hline 司法为民 & sī fă wèi mín \\
\hline 司法院 & sī fă yuàn \\
\hline 四个全面 & sì gè quán miàn \\
\hline 私了 & sī liăo \\
\hline 四人邦 & sì rén bang \\
\hline 私营经济 & sī yíng jīng jì \\
\hline 宋 ～～～～～～～ & sòng \\
\hline 讼师 & sòng shī \\
\hline 隋 & suí \\
\hline 孙逸仙 & sūn yì xiān \\
\hline 太平天国 & tài píng tiān guó \\
\hline 太宗 & tài zōng \\
\hline 唐人 & táng rén \\
\hline 特别经济区 & tè bié jīng jì qū \\
\hline 特别行政区 & tè bié xíng zhèng qū \\
\hline 天道 & tiān dào \\
\hline 天地 & tiān dì \\
\hline 天津 & tiān jīn \\
\hline 天理 & tiān lǐ \\
\hline 天命 & tiān mìng \\
\hline 天人感应 & tiān rén găn yīng \\
\hline 天人合一 & tiān rén hé ȳ̄ \\
\hline 天志 & tiān zhì \\
\hline 天子 & tiān zǐ \\
\hline 调解 & tiáo jiě \\
\hline 调解书 & tiáo jiě shū \\
\hline 调解优先 调判结合 & tiáo jiě yōu xiān tiáo \\
\hline
\end{tabular}




\begin{tabular}{|c|c|}
\hline 铁饭碗 & tiě fàn wăn \\
\hline 同盟会 & tóng méng huì \\
\hline 同文馆 & tóng wén guăn \\
\hline 土地使用权 & tǔ dì shǐ yòng quán \\
\hline 外儒内法 & wài rú nèi fă \\
\hline 万里长城 & wàn lǐ cháng chéng \\
\hline 王守仁 & wáng shǒu rén \\
\hline 魏 & wèi \\
\hline 违法必究 & wéi fă bì jiū \\
\hline 未能事人 焉能事鬼 & wèi néng shì rén yān néng shì guǐ \\
\hline 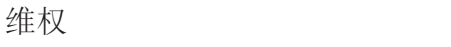 & wéi quán \\
\hline 维稳 & wéi wěn \\
\hline 维新派 & wéi xīn pài \\
\hline 未知生 焉知死 & wèi zhī shēng yān zhī sǐ \\
\hline 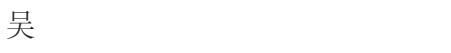 & wú \\
\hline 五常 & wǔ cháng \\
\hline 武昌起义 & wǔ chāng qǐ yì \\
\hline 五代 & wǔ dài \\
\hline 武帝 & wǔ dì \\
\hline 五反 & wǔ făn \\
\hline 五服 & wǔ fú \\
\hline 五伦 & wǔ lún \\
\hline 五四运动 & wǔ sì yùn dòng \\
\hline 无为 & wú wéi \\
\hline 西安 & $x \overline{1} \bar{a} n$ \\
\hline 西安事变 & xī ān shì biàn \\
\hline 习近平 & xí jìn píng \\
\hline 习近平新时代中国特色社会主义 & $\begin{array}{l}\text { xí jìn píng xīn shí dài zhōng guó tè sè shè } \\
\text { huì zhǔ yì }\end{array}$ \\
\hline 西夏 & xī xià \\
\hline 夏 & xià \\
\hline 下海 & xià hăi \\
\hline 厦门 & xià mén \\
\hline 下乡 & xià xiāng \\
\hline 宪法 & xiàn fă \\
\hline 孝 & xiào \\
\hline 小康社会 & xiăo kāng shè huì \\
\hline
\end{tabular}




\begin{tabular}{|c|c|}
\hline 小人 & xiăo rén \\
\hline 心 & xīn \\
\hline 信 & xìn \\
\hline 辛丑条约 & xīn chǒu tiáo yuē \\
\hline 信访 & xìn făng \\
\hline 辛亥革命 & xīn hài gé mìng \\
\hline 信赏必罚 & xìn shăng bì fá \\
\hline 新时代中国特色社会主义 & xīn shí dài zhōng guó tè sè shè huì zhǔ yì \\
\hline 心学 & xīn xué \\
\hline 刑 & xíng \\
\hline 刑部 & xíng bù \\
\hline 行政法规 & xíng zhèng fă guī \\
\hline 行政复议 & xíng zhèng fù yì \\
\hline 行政拘留 & xíng zhèng jū liú \\
\hline 兄弟 & xiōng dì \\
\hline 匈奴 & xiōng nú \\
\hline 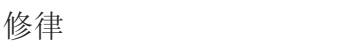 & xiū lǜ \\
\hline 修身 齐家 治国 平天下 & xiū shēn qí jiā zhì guó píng tiān xià \\
\hline 《训政纲领》 & xùn zhèng gāng lǐng \\
\hline 荀子 & xún zĩ \\
\hline 鸦片战争 & yā piàn zhàn zhēng \\
\hline 延安 & yán ān \\
\hline 沿海开放城市 & yán hăi kāi fàng chéng shì \\
\hline 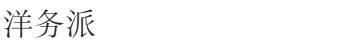 & yáng wù pài \\
\hline 尧 & yáo \\
\hline 义 & yì \\
\hline 一带一路 & yī dài yī lù \\
\hline 以德配天 & yǐ dé pèi tiān \\
\hline 一断于法 & yī duàn yú fă \\
\hline 依法行政 & yī fă xíng zhèng \\
\hline 以法治国 & yǐ fă zhì guó \\
\hline 依法治国 & yī fă zhì guó \\
\hline 以法治吏 & yǐ fă zhì lì \\
\hline 依法执政 & yī fă zhí zhèng \\
\hline 一国两制 & yī guó liăng zhì \\
\hline 一孩政策 & yī hái zhèng cè \\
\hline 义和团 & yì hé tuán \\
\hline
\end{tabular}




\begin{tabular}{|c|c|}
\hline 以民为本 & yǐ mín wéi běn \\
\hline 以人为本 & y̌̌ rén wéi běn \\
\hline 以事实为根据 以法律为准绳 & $\begin{array}{l}\text { yǐ shì shí wéi gēn jù yǐ fă lü wéi zhǔn } \\
\text { shéng }\end{array}$ \\
\hline 因才施教 & yīn cái shī jiào \\
\hline 引礼入法 & yǐn lǐ rù fă \\
\hline 阴阳 & yīn yáng \\
\hline 应当参照 & yīng dāng cān zhào \\
\hline 赢政 & yíng zhèng \\
\hline 有法必依 & yǒu fă bì yī \\
\hline 有法可依 & yǒu fă kě ȳi \\
\hline 有教无类 & yǒu jiào wú lèi \\
\hline 元 & yuán \\
\hline 援法定罪 & yuán fă dìng zuì \\
\hline 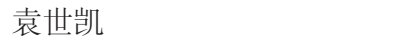 & yuán shì kăi \\
\hline 粤港澳大湾区 & yuè găng ào dà wān qū \\
\hline 《则例》 & zé lì \\
\hline 曾国藩 & zēng guó fān \\
\hline 战国 & zhàn guó \\
\hline 章句 & zhāng jù \\
\hline 张寒 & zhāng qiān \\
\hline 镇江 & zhèn jiāng \\
\hline 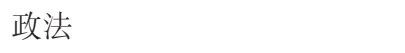 & zhèng fă \\
\hline 政府权力清单 & zhèng fǔ quán lì qīng dān \\
\hline 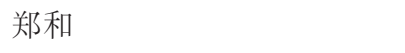 & zhèng hé \\
\hline 正名 & zhèng míng \\
\hline 政治挂帅 & zhèng zhì guà shuài \\
\hline 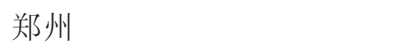 & zhèng zhōu \\
\hline 鷹 & zhì \\
\hline 智 & zhì \\
\hline 指导性案例 & zhǐ dăo xìng àn lì \\
\hline 执法必严 & zhí fă bì yán \\
\hline 执法原情 & zhí fă yuán qíng \\
\hline 职工 & zhí gōng \\
\hline 直辖市 & zhí xiá shì \\
\hline 忠 & zhōng \\
\hline 仲裁 & zhòng cái \\
\hline
\end{tabular}


《重大信条十九条》

中国共产主义青年团

中国梦

中国人民政治协商会议

《中国人民政治协商会议共同纲领》

中国特色社会主义

中国特色社会主义法治

中华民国

中华全国妇女联合会

中华全国总工会

中华苏维埃共和国

中级人民法院

终身负责制

中体西用

中央军事委员会

《中庸》

中西会通

重刑轻民

周

周恩来

周公

纣王

朱德

诸法并存 民刑有分

诸法合体 民刑不分

住房公积金

珠海

朱元璋

朱喜

庄子

紫禁城

自强运动

谘议局

资政院

自治区 zhòng dà xìn tiáo shí jiǔ tiáo

zhōng guó gòng chăn zhǔ yì qīng nián

tuán

zhōng guó mèng

zhōng guó rén mín zhèng zhì xié shāng huì yì

zhōng guó rén mín zhèng zhì xié shāng huì yì gòng tóng gāng lǐng

zhōng guó tè sè shè huì zhǔ yì

zhōng guó tè sè shè huì zhǔ yì fă zhì

zhōng huá mín guó

zhōng huá quán guó fù nừ lián hé huì

zhōng huá quán guó zǒng gōng huì

zhōng huá sū wéi āi gòng hé guó

zhōng jí rén mín fă yuàn

zhōng shēn fù zé zhì

zhōng tǐ xī yòng

zhōng yāng jūn shì wěi yuán huì

zhōng yōng

zhōng xī huì tōng

zhòng xíng qīng mín

zhōu

zhōu ēn lái

zhōu gōng

zhòu wáng

zhū dé

zhū fă bìng cún mín xíng yǒu fēn

zhū fă hé tǐ mín xíng bù fēn

zhù fáng gōng jī jīn

zhū hăi

zhū yuán zhāng

zhū xī

zhuāng ž̀

zǐ jìn chéng

zì qiáng yùn dòng

zī yì jú

zī zhèng yuàn

zì zhì qū 
自治条例

宗法制度

走出去

族规

租赁

最高人民法院

最高人民检察院 zì zhì tiáo lì

zōng fă zhì dù

zǒu chū qù

zú gū̄

zū lìn

zuì gāo rén mín fă yuàn

zuì gāo rén mín jiăn chá yuàn 
Vai I. Lo - 9781785363092 Downloaded from PubFactory at 04/26/2023 10:47:11AM via free access 